ORIGINAL ARTICLE

\title{
NeuroD1 is required for survival of photoreceptors but not pinealocytes: Results from targeted gene deletion studies
}

\author{
Margaret J. Ochocinska, ${ }^{*}$ Estela M. Muñoz, $†$ Shobi Veleri, $\ddagger$ Joan L. Weller,* \\ Steven L. Coon,* Nikita Pozdeyev, $§$ P. Michael Iuvone, $§$ Sandra Goebbels, $\mathscr{I}$ \\ Takahisa Furukawa** and David C. Klein* \\ * Section on Neuroendocrinology, Program in Developmental Endocrinology and Genetics, Eunice \\ Kennedy Shriver National Institute of Child Health and Human Development, National Institutes of \\ Health, Bethesda, MD, USA \\ $\dagger$ Institute of Histology and Embryology, School of Medicine, National University of Cuyo, National \\ Council of Research, Science and Technology (CONICET), ANPCyT, Mendoza, Argentina \\ $\ddagger$ Neurobiology-Neurodegeneration and Repair Laboratory, National Eye Institute, National Institutes \\ of Health, Bethesda, MD, USA \\ §Department of Ophthalmology and Pharmacology, Emory University School of Medicine, Atlanta, GA, \\ USA \\ IIDepartment of Neurogenetics, Max-Planck-Institute of Experimental Medicine, Göttingen, Germany \\ **Institute for Protein Research \& CREST-JST, Osaka University, Osaka, Japan
}

\begin{abstract}
NeuroD1 encodes a basic helix-loop-helix transcription factor involved in the development of neural and endocrine structures, including the retina and pineal gland. To determine the effect of NeuroD1 knockout in these tissues, a Cre/loxP recombination strategy was used to target a NeuroD1 floxed gene and generate NeuroD1 conditional knockout (cKO) mice. Tissue specificity was conferred using Cre recombinase expressed under the control of the promoter of $\mathrm{Crx}$, which is selectively expressed in the pineal gland and retina. At 2 months of age, NeuroD1 cKO retinas have a dramatic reduction in rod- and cone-driven electroretinograms and contain shortened and disorganized outer segments; by 4 months, NeuroD1 cKO retinas are devoid of photoreceptors.
\end{abstract}

In contrast, the NeuroD1 cKO pineal gland appears histologically normal. Microarray analysis of 2-month-old NeuroD1 cKO retina and pineal gland identified a subset of genes that were affected 2-100-fold; in addition, a small group of genes exhibit altered differential night/day expression. Included in the down-regulated genes are Aip/1, which is necessary to prevent retinal degeneration, and Ankrd33, whose protein product is selectively expressed in the outer segments. These findings suggest that NeuroD1 may act through Aip/1 and other genes to maintain photoreceptor homeostasis.

Keywords: gene expression, microarray, NeuroD1, pineal gland, retina, transcriptome profiling.

J. Neurochem. (2012) 123, 44-59.
Received April 25, 2012; revised manuscript received June 20, 2012; accepted July 6, 2012.

Address correspondence and reprint requests to Dr. David Charles Klein, Section on Neuroendocrinology, Program in Developmental Endocrinology and Genetics, The Eunice Kennedy Shriver National Institute of Child Health and Human Development, National Institutes of Health, 49 Convent Drive, Room 6A82, Bethesda, MD 20892-4510, USA. E-mail: kleind@mail.nih.gov
Abbreviations used: bHLH, basic helix-loop-helix; BrdU, bromodeoxyuridine; cKO, conditional knockout; CON, control; DAPI, 4',6diamidino-2-phenylindole; ERG, electroretinogram; GCL, ganglion cell layer; INL, inner nuclear layer; ONL, outer nuclear layer; RPE, retinal pigment epithelium; TEM, transmission electron microscopy; ZT, Zeitgeber time. 
NeuroD1 is a basic helix-loop-helix (bHLH) transcription factor implicated in cell cycle regulation, retinal cell genesis, and neuronal development (Miyata et al. 1999; Schwab et al. 2000; Lee et al. 2000; Cai et al. 2000; Liu et al. 2000; Cherry et al. 2011; Ochocinska and Hitchcock 2009). In the retina, NeuroDl plays a role in terminal photoreceptor differentiation and survival of rod photoreceptors; loss of NeuroD1 results in progressive photoreceptor degeneration (Morrow et al. 1999; Pennesi et al. 2003). NeuroD1 also functions in cone photoreceptor patterning and mediates cone-specific expression through the regulation of thyroid hormone receptor $\beta 2$ expression during development (Liu et al. 2008).

NeuroD1 mRNA is also highly abundant in the pineal gland and exhibits a developmental expression pattern similar to that of the retina (Bailey et al. 2009; Muñoz et al. 2007). This is consistent with the common evolutionary origin of pinealocytes and retinal photoreceptors (Klein 2006; Bailey et al. 2009; Donoso et al. 1985; Korf et al. 1985, 1992; Rodrigues et al. 1986; Reig et al. 1990; Schaad et al. 1991; Babila et al. 1992; Lolley et al. 1992). In contrast to the retina, the pineal gland is a relatively homogeneous structure, composed $95 \%$ of pinealocytes, which share some genetic features with photoreceptors. This makes the pineal gland a useful model for understanding elements of cell biology shared by both tissues.

Previous studies directed at understanding the role of NeuroD1 in the mouse retina have used a global knockout strategy that eliminates NeuroDl expression in all tissues, including the pancreas and cerebellum (Morrow et al. 1999; Liu et al. 2008). The majority of these animals die shortly after birth, which limits efforts to study NeuroD1 function in the adult. Moreover, global knockout of NeuroD1 allows the possibility that the effects of this manipulation on the retina are mediated by non-retinal and non-pineal tissues.

To obviate this possibility in this study, a Cre/loxP recombination strategy was used to limit gene deletion to the pineal gland and retina. Cre recombinase was selectively expressed in pinealocytes and retinal cells, including photoreceptors, by placing it under control of the Crx promoter, which is selectively expressed in both tissues late in gestation (Omori et al. 2012; Rath et al. 2006; Furukawa et al. 2002). Crx-cre mice were crossed with NeuroD1 $1^{\text {flox/flox }}$ mice (Goebbels et al. 2005) to generate NeuroD $1^{\text {flox/flox }} / \mathrm{Crx}$-cre ${ }^{+}$conditional knockout (cKO) and NeuroDI $1^{\text {flox/flox }} /$ Crx -cre $e^{-}$control mice. The effects of NeuroD1 cKO on the retina and pineal gland were monitored histologically by immunofluorescence and transmission electron microscopy, and by microarray-based gene expression profiling. Retinal function was monitored using electroretinography. The findings of these studies are presented below.

\section{Materials and methods}

\section{Animals}

All animal experiments and treatments were performed in accordance with the National Institutes of Health Guide for Care and Use of Laboratory Animals and the Animal Research: Reporting In vivo Experiments (ARRIVE) guidelines. Mice were housed in a 12:12 light-dark cycle with lights on at Zeitgeber time (ZT) 0 , and food and water ad libitum. Both male and female mice were used for all experiments.

NeuroD1 cKO mice: A colony of mice was established on a C57BL/ $6 \mathrm{~J}$ background using a male NeuroD $1^{\text {floxfflox }}$ animal in which exon 2 of the NeuroD1 gene, which includes the initiating codon, is flanked by two loxP sites (Goebbels et al. 2005). These animals were crossed with Crx-cre mice (Omori et al. 2012), which express Cre recombinase under the control of the 2-kb Crx promoter (Furukawa et al. 2002). See Fig. 1a and Appendix S1 for further details.

$A g r 2^{-/-}$mice: A colony of $A g r 2^{-/-}$mice was established by crossing a male $\mathrm{Agr}^{+/-}$animal (Dr. David J. Erle, University of California, San Francisco) with a C57BL/6J female (Taconic Farms, Germantown, NY, USA) to generate heterozygous progeny (Lewandoski et al. 1997; Park et al. 2009). These heterozygous progeny were used to generate $\mathrm{Agr} \mathrm{C}^{-/-}(\mathrm{Agr} 2 \mathrm{KO})$ and age-matched wildtype littermate control animals; see Appendix S1 for further details.

\section{Microarray analysis}

Pineal glands and retinas from 2-month-old NeuroD1 cKO and control mice were removed during the day at ZT6 and at night at ZT20; tissue was placed on solid $\mathrm{CO}_{2}$. Tail samples were collected in parallel for genotype confirmation; see Appendix S1 for further details.

Total RNA ( $200 \mathrm{ng} /$ pineal gland and $1000 \mathrm{ng} /$ retina) was prepared from pools of six pineal glands or retinas; three pools per organ and per genotype were analyzed at each sampling time. Published methods were used for total RNA isolation, quality control, and cDNA amplification (Rovsing et al. 2011); see Appendix S1 for further details. Amplified cDNA was biotinylated using the Encore ${ }^{\mathrm{TM}}$ Biotin Module (NuGEN Technologies, Inc., San Carlos, CA, USA). Biotinylated cDNA $(20 \mu \mathrm{g})$ was fragmented and hybridized for $18 \mathrm{~h}$ at $45^{\circ} \mathrm{C}$ to the GeneChip Mouse Genome Array 4302.0 (Affymetrix, Santa Clara, CA, USA). This GeneChip contained 45000 probe sets corresponding to 39000 transcripts and variants from over 34000 annotated mouse genes. The arrays were stained and washed as described in the Affymetrix protocols.

\section{Data analysis}

Affymetrix arrays were scanned using a GeneChip Scanner 3000 (Affymetrix). For each array, the raw signal intensity (.CEL) files were generated and analyzed using Genomatix ChipInspector V2.0 software (Munich, Germany). The following filters were used for all analyses: exhaustive matching, a false-discovery rate $=0$, cutoff $=1$, region size $=300 \mathrm{bp}$, and a minimum of four significant probes. Differences with $p<0.05$ were considered to be statistically significant; see Appendix S1 for further details. The microarray data are available at the NCBI Gene Expression Omnibus (Edgar et al. 2002) and are accessible through GEO Series accession number GSE35396 (http://www.ncbi.nlm.nih.gov/geo/query/acc.cgi?acc= GSE35396). 
Promoter and transcription factor analyses were done using the following Genomatix Software Suite modules: Genes2Promoter, RegionMiner, and MatInspector. Briefly, the results from ChipInspector were loaded into the Genes2Promoter program to identify networks and pathways. RegionMiner was used to identify transcription factor module enrichment from the list of differentially expressed genes and MatInspector was used to inspect the relevant promoter regions.

\section{Quantitative real-time polymerase chain reaction}

Twenty differentially expressed transcripts $(p<0.05)$ were validated by qRT-PCR using the LightCycler ${ }^{\circledR} 480$ Rapid Thermal Cycler System (Roche, Indianapolis, IN, USA). The SPIA-amplified cDNA generated for the Microarrays was used as template for all qRT-PCR experiments. PCR reactions were performed in a $25 \mu \mathrm{L}$ volume consisting of $0.5 \mu \mathrm{mol} / \mathrm{L}$ primers (Table 1), Real-Time $\mathrm{SYBR}^{\circledR}$ Green PCR Master Mix (SuperArray Bioscience, Frederick, MD, USA), and cDNA as per the manufacturer's instructions. Published methods were used for all assays (Muñoz et al. 2007); see Appendix S1 for further details.

\section{Immunohistochemistry}

All immunohistochemistry protocols were performed as previously described (Ochocinska and Hitchcock 2009). Sections were stained with the following antisera: mouse monoclonal anti-Rho (Rho 4D2; Dr. Robert Molday, University of British Columbia, Vancouver, Canada) diluted 1:1000; rabbit polyclonal anti-Mopsin and anti-S-opsin (Dr. Cheryl Craft, University of Southern California, Los Angeles), diluted 1:1000. Secondary antisera included goat anti-rabbit Alexa Fluor ${ }^{\circledR} 488$ and goat anti-mouse Alexa Fluor $\left.^{(}\right) 555$ (Invitrogen, Eugene, OR, USA), diluted $1: 200$. The stained tissue sections were visualized under an LSM 510 META Laser Scanning Confocal Microscope (Carl Zeiss, Maple Grove, MN, USA); see Appendix S1 for further details.

\section{Bromodeoxyuridine labeling}

Bromodeoxyuridine (BrdU) (Sigma, St. Louis, MO, USA) was injected intraperitoneally $(0.1 \mathrm{mg} \mathrm{BrdU} / \mathrm{g}$ body wt) at post-natal day 0 (P0) and at 2 months of age. The animals were killed $4 \mathrm{~h}$ post injection. Three animals per genotype were analyzed (cKO, $n=3$; CON, $n=3$ ) at both ages.

\section{Western blot}

Retina tissue was homogenized and $100 \mu \mathrm{g}$ sample of retinal protein was separated by sodium dodecyl sulfate-polyacrylamide gel electrophoresis. Blots were incubated with a $1: 5000$ dilution of affinity-purified Rho 4D2 antiserum overnight at $4{ }^{\circ} \mathrm{C}$, followed by a 1-2-h incubation with Alexa Fluor ${ }^{\circledR} 680$ goat anti-mouse IgG secondary antibody, diluted $1: 15000$. Immunoreactive proteins were detected using the Odyssey Infrared Imaging System (Li-Cor; Lincoln, NE, USA) and analyzed by video densitometry (Lynx software; Applied Imaging, Newcastle-uponTyne, UK). For semiquantitative analysis, blots were stripped and reprobed with a monoclonal antibody against beta-actin (Sigma), diluted 1:1000, and Alexa Fluor ${ }^{\circledR} 800$ goat anti-mouse IgG secondary antibody, diluted $1: 5000$; see Appendix S1 for further details.

\section{Transmission electron microscopy}

Pineal glands were dissected and fixed $\left(1 \mathrm{~h}\right.$ at $4^{\circ} \mathrm{C}$ in $2.5 \%$ glutaraldehyde, made in $0.1 \mathrm{M}$ sodium cacodylate buffer, $\mathrm{pH}$ 7.4). Eyes were dissected and a slit was made in the superior cornea prior to fixation $\left(2 \mathrm{~h}\right.$ at $4^{\circ} \mathrm{C}$ in fixation mix). After the 2-h primary incubation, the superior cornea was cut away, the lens was removed, and fixation was continued at $4^{\circ} \mathrm{C}$ overnight. Tissues were embedded and polymerized in $100 \%$ resin for $18 \mathrm{~h}$ in a lab oven set at $70^{\circ} \mathrm{C}$. Thin sections (50-nm thick) were cut on a Reichert-Jung Ultracut-E ultramicrotome (Leica, Wetzlar, Germany) and collected on LuxFilm grids (30-nm film thickness, Ted Pella, Inc., Redding, CA,USA). The grids were post-stained with uranyl acetate and lead citrate and examined using a Tecnai G2 transmission electron microscope operating at $80 \mathrm{kV}$ (FEI, Hillsboro, OR, USA); see Appendix S1 for further details.

\section{Electroretinography}

Published methods were used for electroretinography (Pang et al. 2005). See Appendix S1 for further details.

\section{Statistics}

$\log _{2}$-transformed microarray data from control and NeuroD1 cKO groups, at ZT6 and ZT20, were compared using two-way ANOVA on GraphPad Prism V4 (GraphPad Software Inc., San Diego, CA, USA). The statistical significance of the microarray, qRT-PCR, and Western blot results was determined by a Student's two-tailed $t$-test with Welch's correction (Armitage et al. 2002). Electroretinogram (ERG) results were compared using two-way ANOva on GraphPad Prism V4 (GraphPad software) with $p$-values of $<0.05$ considered statistically significant.

\section{Results}

\section{Morphological studies}

\section{The NeuroD1 cKO mouse retina has marked} morphological changes

To characterize the retinal morphology of NeuroDl cKO mice, retinal sections from three animals per genotype were analyzed (cKO, $n=3$; CON, $n=3$ ). Histological analysis revealed that the outer nuclear layer (ONL) in the NeuroD1 cKO retina is present at 2 months of age, although the observed thickness varies (Fig. 1b, middle panels). However, the ONL is absent at 4 months of age (Fig. 1b, right panels). The inner nuclear layer, inner plexiform layer, and ganglion cell layer (GCL) are not affected in the NeuroD1 cKO retina based on histological evaluation via light microscopy (Fig. 1b) and transmission electron microscopy, comparing the cellular structures in all three retinal layers, including the ganglion cell layer, inner nuclear layer, and outer nuclear layer (data not shown). Specifically, we examined the morphology of the cells within the respective layers, the organelles within the cells including mitochondria and endoplasmic reticulum, and the relationship between respective cells. Because of the absence of the 


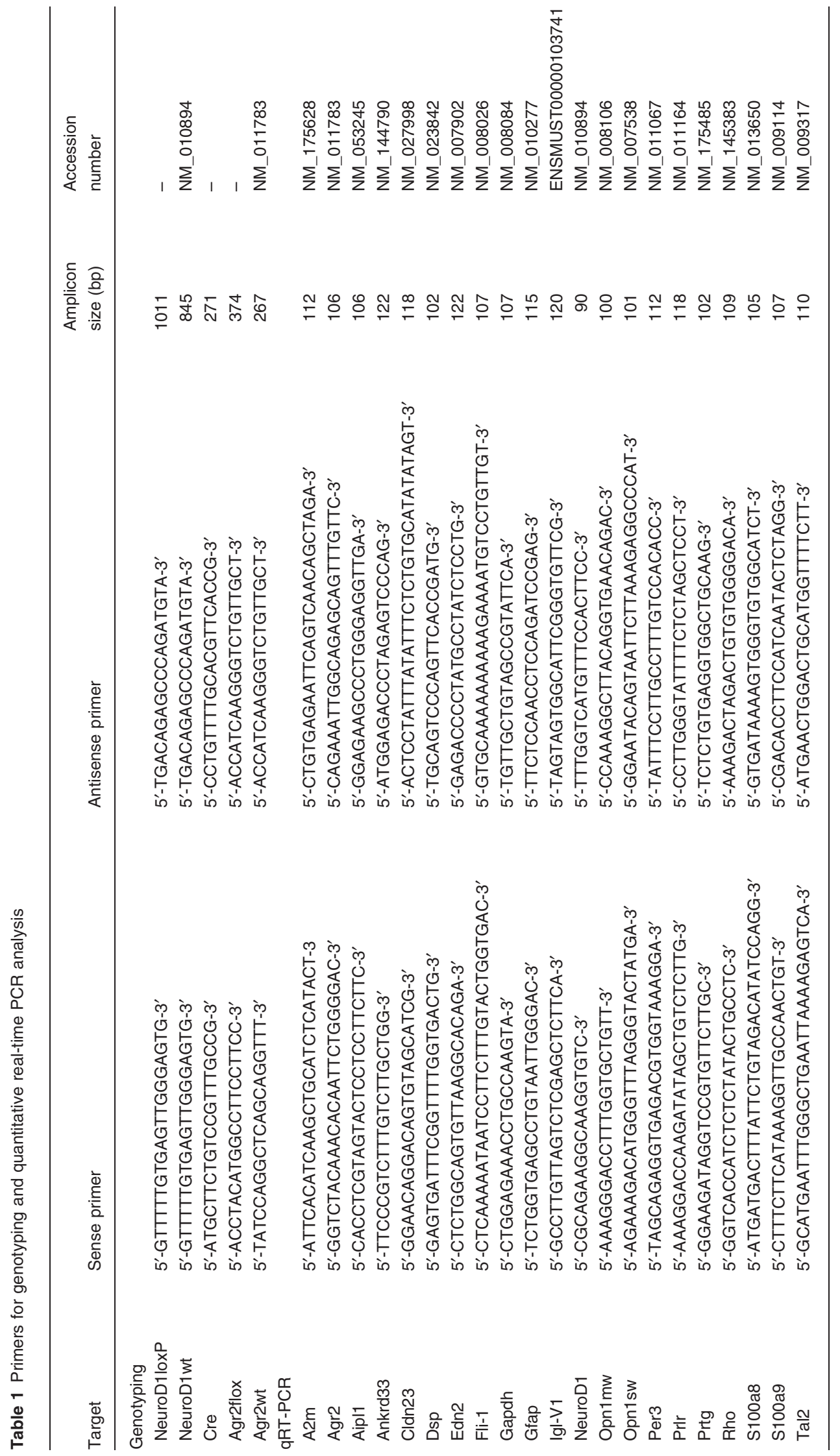


(a)

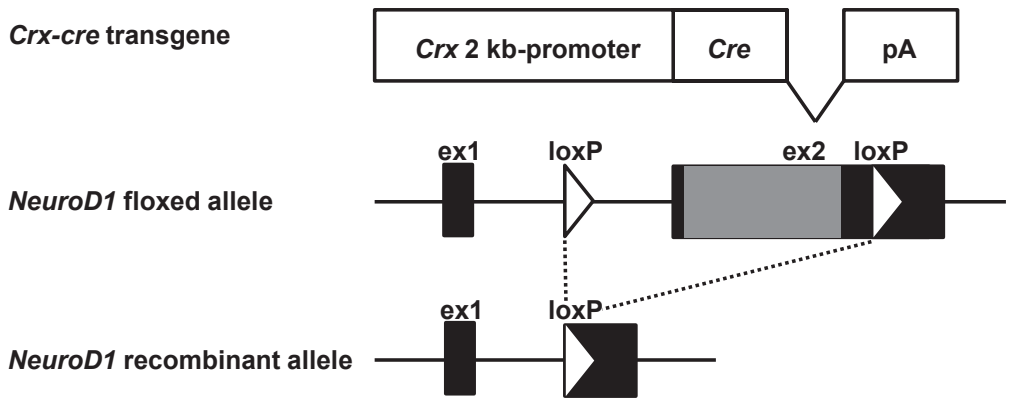

(b)
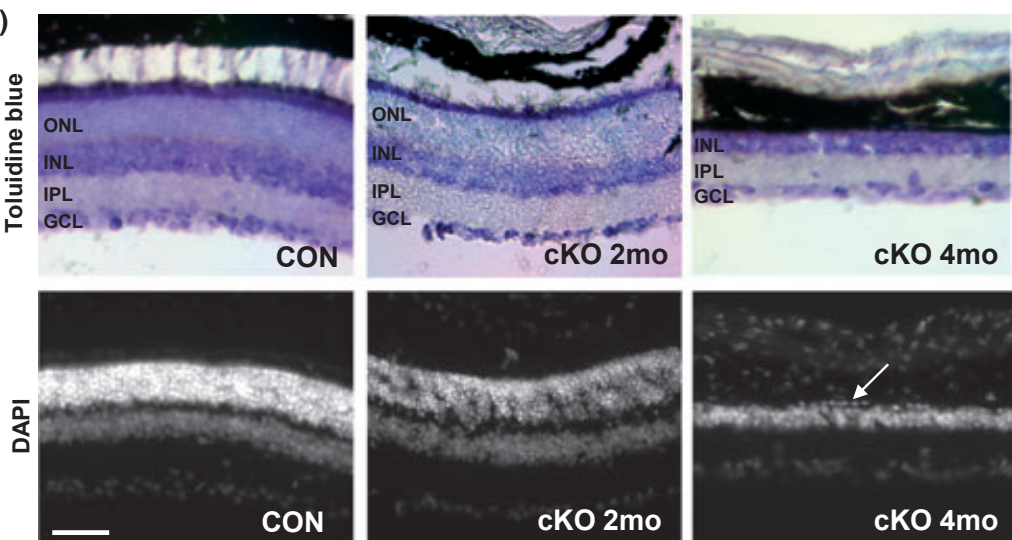

Fig. 1 Generation of NeuroD1 conditional knockout mice. (a) Schematic of constructs. Mice expressing Cre recombinase under the control of the Crx 2-kb promoter were crossed with the NeuroD $1^{\text {flox }}$ mouse line, in which the second exon of the NeuroD1 gene is flanked by two loxP sites. We obtained NeuroD $1^{\text {flox/flox}} / \mathrm{Crx}$ - $\mathrm{Cre}^{+}$mice as NeuroD1 conditional knockout (cKO) mice by mating NeuroD $1^{\text {flox/flox }}$ mice with NeuroD1/fllox $/ \mathrm{Crx}$-cre $e^{+}$mice. (b) Retina sections from 2month-old control and 2-and 4-month-old NeuroD1 cKO mice were

ONL by 4 months of age, subsequent evaluation of cone and rod photoreceptors was limited to 2-month-old retinas.

Cone receptors were examined using antisera against cell type-specific markers M-opsin (Opn1mw) and S-opsin (Opn1sw). M-opsin antisera labeled the outer segments of medium wavelength cone photoreceptors in control retinas. In contrast, in the cKO retina, M-opsin immunoreactivity was nearly undetectable (compare Fig. 2a and b). The expression of M-opsin mRNA was reduced by $80 \%$ in the cKO retina compared with controls (Fig. 2c). S-opsin antisera labeled cone outer segments in 2-month-old control and NeuroD1 cKO retinas. However, the outer segments labeled with Sopsin were disorganized; in addition, the S-opsin protein was also mislocalized to the cell membrane and synapse (compare Fig. $2 \mathrm{~d}$ and e). The expression level of S-opsin transcript in the cKO and control retinas was similar (Fig. 2f).

Rods were examined at 2 months of age using antisera against the rod-specific marker Rho. Retinal sections from three animals per genotype were analyzed (cKO, $n=3$; $\mathrm{CON}, n=3$ ). The control retina showed a strong Rho signal (Fig. 2g). In contrast, the NeuroDl cKO retina showed a stained with toluidine blue (top three panels) and DAPI (bottom three panels). The outer nuclear layer (ONL) is present in 2-month-old control and NeuroD1 cKO retinas, respectively (left and middle panels). Histology reveals the absence of the ONL by 4 months in NeuroD1 cKO retinas (arrow, right panel). The inner nuclear layer (INL), inner plexiform layer (IPL), and the ganglion cell layer (GCL) are not affected. Scale bar: $50 \mu \mathrm{m}$. See Appendix S1 for further details.

weak Rho signal and the protein appeared to be partially mislocalized to the inner segments (Fig. 2h). The Rhopositive outer segments of the NeuroDl cKO retina were also shortened and disorganized compared with the controls (Fig. 2h). The red label in the GCL of control and cKO retinas is consistent with the staining pattern of Müller glia end feet.

The immunohistological findings were confirmed by Western blot, which revealed that Rho protein in the 2month-old NeuroDl cKO retina was significantly reduced relative to control (estimated by dilution analysis to be $\sim 95 \%$ ), (Fig. 2i). In contrast, Rho mRNA was reduced by only $40 \%$ (Fig. 2j).

\section{Ultrastructural analysis of retinal degeneration in 2-month-old NeuroD1 cKO mice}

Ultrastructural evaluation of retinas from conditional $\mathrm{Neu}$ roD1 cKO and control mice was performed using transmission electron microscopy. Retinal sections from three animals per genotype were analyzed (cKO, $n=3$; CON, $n=3$ ). No change in the inner nuclear layer and ganglion 

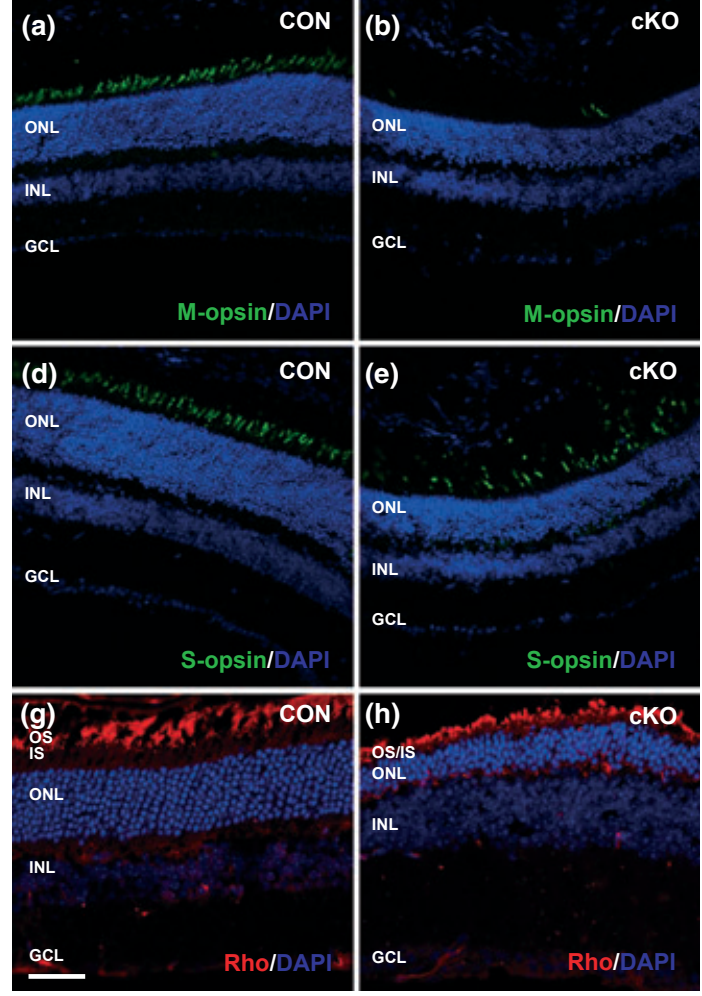

Fig. 2 Effect of NeuroD1 conditional knockout on photoreceptors. (a) $\mathrm{M}$-opsin protein is expressed in outer segments of medium wavelength cones in control retinas. (b) Conditional knockout of NeuroD1 results in depletion of medium wavelength cones. (c) The expression of M-opsin mRNA is reduced in conditional knockout (cKO) retinas compared with controls, as shown by qRT-PCR. (d) S-opsin protein is expressed in the outer segments of short wavelength cones in control retinas. (e) Conditional knockout of NeuroD1 results in depletion of short wavelength cones. S-opsin protein is also mislocalized to the cell membrane and synapse. (f) There is no change in the expression of $\mathrm{S}$-opsin mRNA in cKO retinas compared to controls, as shown by

cell layer was apparent at the ultrastructural level (data not shown). In the NeuroDl cKO retina, the outer segments were disorganized, shortened in length, and, in some regions, completely absent; the controls, in contrast, showed normal outer segments (compare Fig. 3a and c with Fig. 3b and d). The structural integrity of the outer segment disks appears altered and atypical whorls of membranous material (arrows in Fig. 3d) were present between the outer segments and the retinal pigment epithelium. This expansion of amorphous membranous material is also illustrated in Fig. $3 \mathrm{e}$ and at a higher magnification in Fig. $3 f$.

\section{Ultrastructural analysis of the pineal gland in 2-month-old NeuroD1 cKO mice}

To determine if there were any changes in pineal gland morphology between genotypes, pineal gland sections from three animals per genotype were analyzed (cKO, $n=3$;
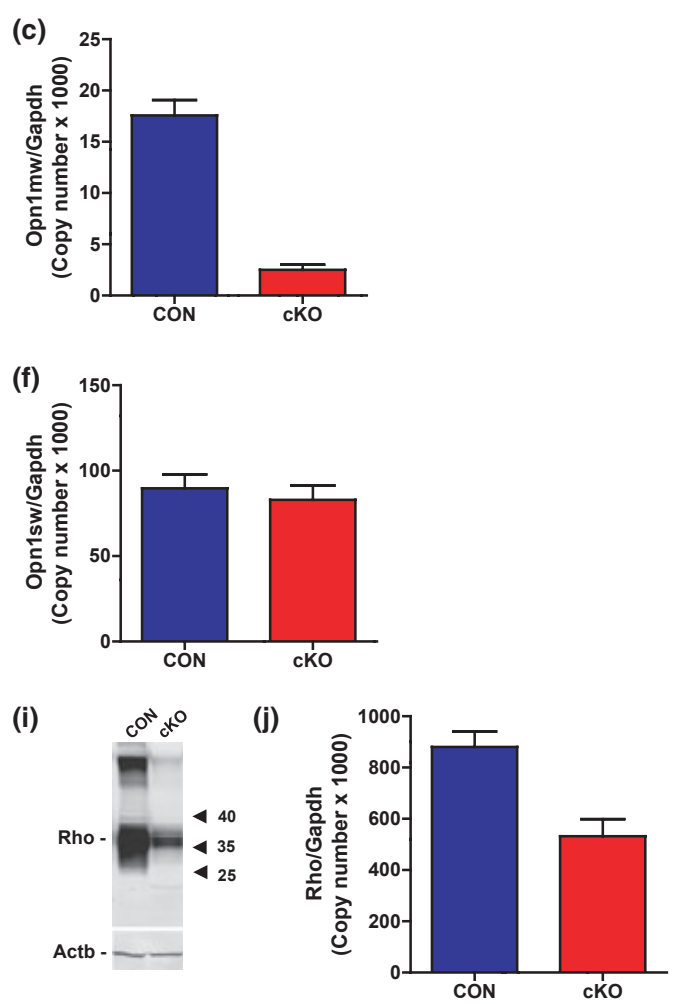

qRT-PCR. (g) Rho protein is expressed in the outer segments of rod photoreceptors in the control retina. (h) In the cKO retina, Rho protein is expressed in both the inner segments and outer segments, which appear shortened compared with controls. (i) Rho protein is decreased $95 \%$ in the cKO retina compared with the control retina, as shown by Western blotting using dilution analysis. The lower band is the actin loading control. (j) The expression of Rho mRNA is reduced by $\sim 40 \%$ in the cKO retinas compared with controls, as shown by qRT-PCR. DAPI (blue); M-opsin (green in a and b); S-opsin (green in c and d); Rho (red in e and f). Scale bar: $50 \mu \mathrm{m}$. See Appendix $\mathrm{S} 1$ for further details.

CON, $n=3$ ). In contrast to the striking photoreceptor degeneration phenotype observed in the NeuroDl cKO retina, there was no obvious change in the morphology of the pineal gland body in NeuroDl cKO compared to control mice at the light microscopy level (Fig. 4a and 4b). The pineal stalk was shorter and wider in the NeuroD1 cKO animals compared with controls (compare Fig. 4a with Fig. 4b). However, this observation could not be statistically quantified because of the variability in the pineal stalk morphology, and associated technical limitations.

BrdU was used to label mitotically active cells (Wojtowicz and Kee 2006) with the intention of detecting differences between control and NeuroDl cKO animals. Injections were performed at post-natal day zero and at 2 months of age. Brain sections from three animals per genotype and age group were analyzed (cKO, $n=3 ; \mathrm{CON}, n=3)$. BrdU 

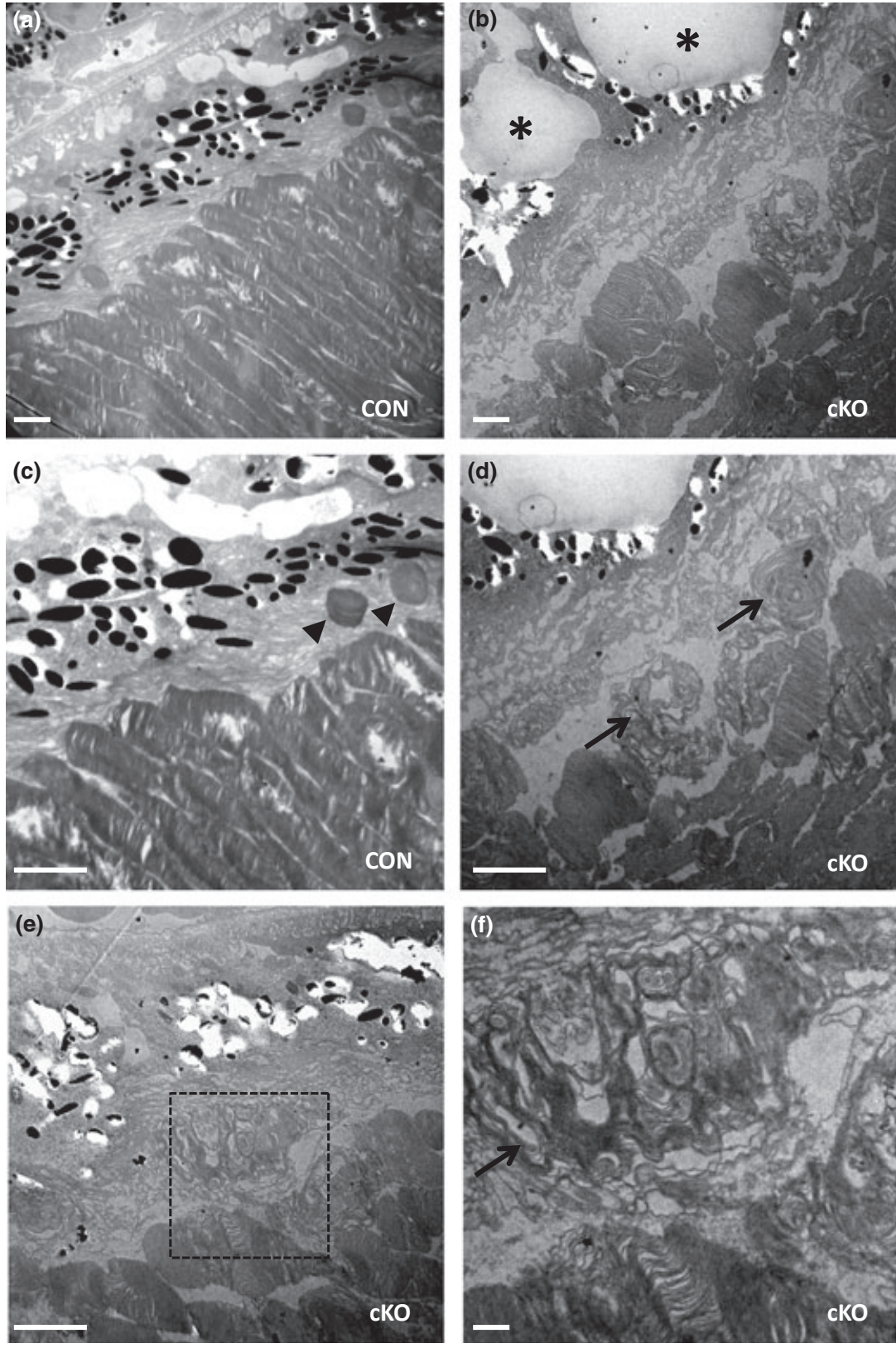

Fig. 3 Changes in ultrastructure of $\mathrm{Neu}$ roD1 conditional knockout (cKO) retina at 2 months of age. ( $a$ and c) Organized outer segments are present in the control retina. Phagosomes can be observed (arrow heads) during the disk-shedding process. (b and d) The outer segments in the cKO retina are disorganized and form membranous whorls (arrows). Note the absence of phagosomes and disk shedding. The asterisks label large vacuoles indicative of retinal degeneration. (e) Long retinal pigment epithelium processes extend towards the outer segment whorls of the cKO retina. (f) An enlargement of the region framed by the box (dashed line) in (e) emphasizing the amorphous processes in this area (arrows). Scale bars: (a-e) $2 \mu \mathrm{m}$, (f) $0.5 \mu \mathrm{m}$. See Appendix $\mathrm{S} 1$ for further details. labeling of the control and cKO pineal stalk at both developmental stages was not different (data not shown). This suggests that the pineal stalk phenotype observed in the NeuroD1 cKO animals is not associated with a difference in proliferation.

Ultrastructural evaluation of pineal glands from 2-monthold NeuroDl cKO and control mice was performed using transmission electron microscopy. Pineal gland sections from three animals per genotype were analyzed (cKO, $n=3$; CON, $n=3$ ). The morphology of pinealocytes and blood vessels in both groups was normal (Møller et al. 1978), as judged by examination of the relationship of pinealocytes to each other and to vascular elements and the appearance of cellular components including the nucleus, mitochondria, ER, membranes, and vesicles (Fig. 4c and 4d).

\section{Gene profiling studies}

\section{Deletion of NeuroD1 alters the retinal and}

pineal transcriptomes

The influence of NeuroD1 on the retina and pineal gland transcriptomes was assessed by Affymetrix microarray analysis in 2-month-old control and NeuroDl cKO mice. This revealed that NeuroDl transcript abundance was reduced by $>20$-fold in both the retina and pineal gland, confirming the effectiveness of the KO strategy. 
Fig. 4 Morphology and ultrastructure of 2month-old NeuroD1 conditional knockout (cKO) and control pineal gland. (a and b) DAPI-stained (blue) section of brains from 2-month-old control and NeuroD1 cKO mice, respectively, showing the pineal gland and stalk. (c) Control pineal gland with endocrine characteristics including blood vessels and pinealocytes. (d) The NeuroD1 cKO pineal gland also contains a normal complement of pinealocytes, endothelial cells, red blood cells, and nerve fibers. Scale bar: ( $a$ and b) $200 \mu \mathrm{m}$, (c and d): $2 \mu \mathrm{m}$. PG, pineal gland; Pin, pinealocyte; CP, choroid plexus; E, endothelial cell; $\mathrm{RB}$, red blood cell; NF, nerve fiber. See Appendix $\mathrm{S} 1$ for further details.
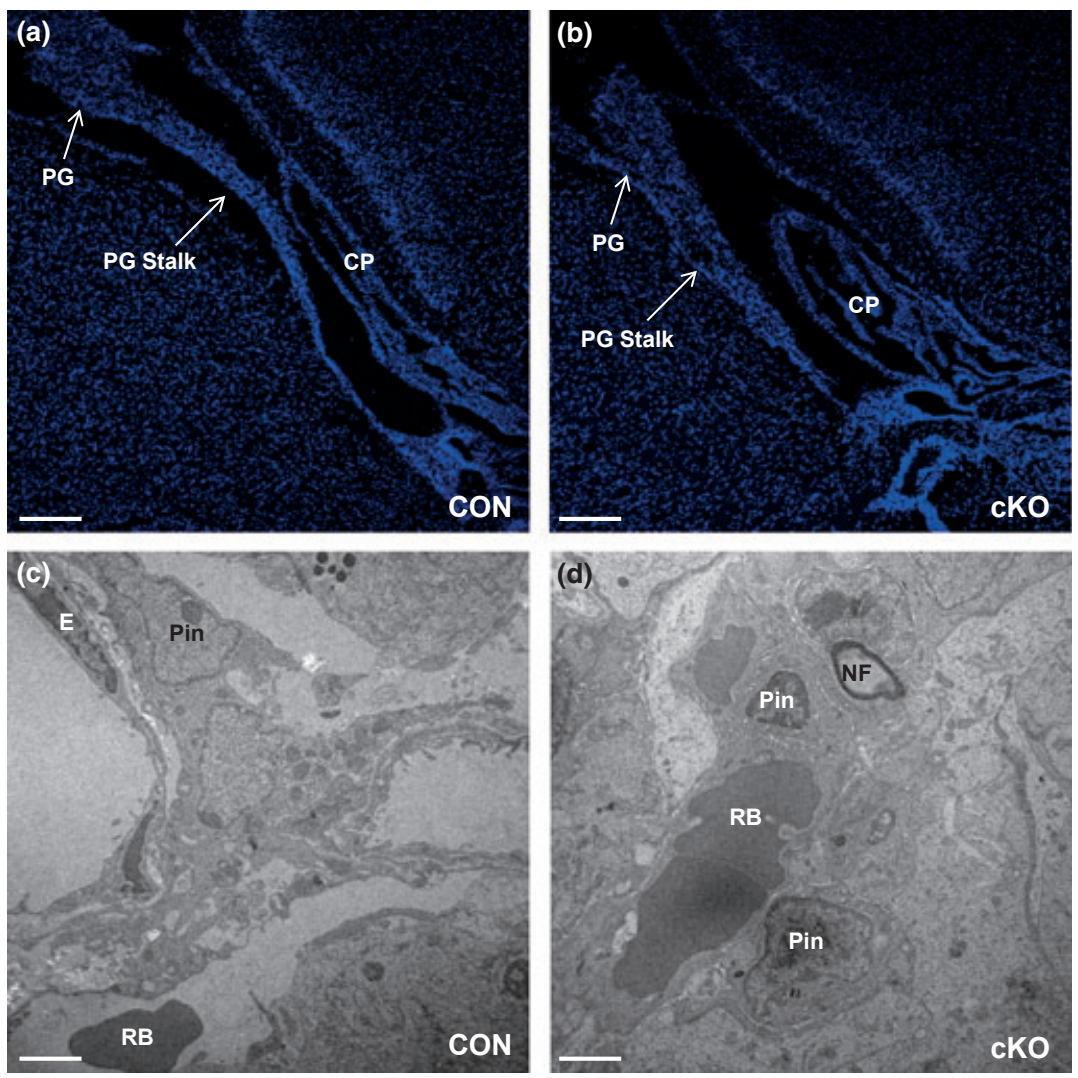

The microarray results identified several potential downstream target genes. In the retina, the expression of 55 genes was reduced $>$ two-fold, including genes linked to transcription, phototransduction, and protein folding (Table 2). The most dramatically down-regulated genes included Ankrd33/ Panky (7.8-fold) and Agr2 (7.9-fold), which are associated with retinal transcription (Sanuki et al. 2010) and protein folding (Persson et al. 2005), respectively. The following phototransduction-linked genes did not decrease more than two-fold, including Rho, Gnat1, Rcvrn, Sag, Arr3, Pde6, and Grk1.

In addition to down-regulated genes, it was observed that some genes were up-regulated in the retina. The most highly up-regulated gene in the retina was the T-cell marker Tal2 (11.8-fold); others include Gfap (5.4-fold), Prtg (5.7-fold), Edn2 (7.4-fold), and $A 2 m$ (7.6-fold), all of which are associated with the immune response (Bucher et al. 2000; Kumar and Shamsuddin 2012; Takahashi et al. 2010; Rattner and Nathans 2005; Fan et al. 2010).

In the NeuroD1 cKO pineal gland, the expression of 16 genes was reduced $>$ two-fold (Table 2), including genes linked to transcription and calcium signaling. The most dramatically down-regulated genes included Agr2 (2.2-fold), S100a8 (3.3-fold), and S100a9 (3.1-fold). The most upregulated gene in the pineal gland was $I g l-V I$ (9.1-fold), a member of the immunoglobulin family linked to the immune response (Das et al. 2011).
A set of 32 genes exhibited a night/day difference in expression in the control retina; 10 of these genes were also rhythmic in the NeuroD1 cKO retina. Eleven genes that were rhythmic in the NeuroDl cKO retina did not show daily variations in the control retina at the time points studied (Table 3). In the control pineal gland, a set of 38 genes exhibited differential night/day expression; 28 of these genes also exhibited daily rhythms in the NeuroD1 cKO pineal gland. In addition, 14 genes were only rhythmic in the NeuroD1 cKO pineal gland (Table 3).

Microarray gene results were validated by qRT-PCR (Table 2). The transcripts examined were those that were most strongly impacted by the NeuroD1 deletion. In all cases, the results from qRT-PCR analysis qualitatively confirmed the changes observed. For some transcripts, the differences in expression detected by qRT-PCR were $>$ four-fold greater than those revealed by microarray analysis.

In silico promoter analysis of genes affected in NeuroD1 cKO retina and pineal gland

The list of differentially regulated genes in the NeuroD1 cKO retina and pineal gland, shown in Table 2, was analyzed using the Genomatix Pathway System (GePS). Transcription factor binding sites were determined using RegionMiner, in Genomatix, which compares the promoter regions of the 
Table 2 Differentially expressed genes in 2-month-old NeuroD1 cKO retina and pineal gland. (A) qRT-PCR validation of the ten most differentially expressed genes in the NeuroD1 cKO retina, including genes linked to transcription, phototransduction, and protein folding. (B) qRT-PCR validation of the ten most differentially expressed genes in the NeuroD1 cKO pineal gland, including genes linked to transcription and calcium signaling

\begin{tabular}{|c|c|c|c|c|}
\hline $\begin{array}{l}\text { Gene } \\
\text { Symbol }\end{array}$ & Gene Title & $\begin{array}{l}\text { Affymetrix } \\
\text { Fold Change }\end{array}$ & $\begin{array}{l}\text { qRT-PCR } \\
\text { Fold Change }\end{array}$ & GO Biological Process Description \\
\hline \multicolumn{5}{|c|}{ A. Retina: Differentially expressed genes in cKO versus CON } \\
\hline NeuroD1 & $\begin{array}{l}\text { Neurogenic differentiation } \\
1 \text { transcription factor }\end{array}$ & -14.6 & -26.9 & $\begin{array}{l}\text { Transcription activator activity, } \\
\text { Photoreceptor cell development }\end{array}$ \\
\hline Agr2 & $\begin{array}{l}\text { Anterior gradient homolog } 2 \\
\text { (Xenopus laevis) }\end{array}$ & -7.9 & -101.9 & Protein binding \\
\hline Ankrd33 & $\begin{array}{l}\text { Ankyrin repeat domain 33; } \\
\text { Panky }\end{array}$ & -7.8 & -9.9 & Transcriptional cofactor \\
\hline Cldn23 & Claudin 23 & -7.3 & -37.2 & Calcium-independent cell-cell adhesion \\
\hline Opn1mw & $\begin{array}{l}\text { Opsin } 1 \text { (cone pigments), } \\
\text { medium-wave-sensitive }\end{array}$ & -4.4 & -8.6 & Phototransduction \\
\hline Aipl1 & $\begin{array}{l}\text { Aryl hydrocarbon receptor } \\
\text { interacting protein-like } 1\end{array}$ & -3.0 & -3.8 & Phototransduction \\
\hline Gfap & Glial fibrillary acidic protein & 5.4 & 7.0 & Structural constituent of cytoskeleton \\
\hline Prtg & Protogenin & 5.7 & 6.4 & Multicellular organismal development \\
\hline Edn2 & Endothelin-2 & 7.4 & 9.9 & Cell surface receptor-linked signaling pathway \\
\hline $\mathrm{A} 2 \mathrm{~m}$ & Alpha-2-macroglobulin & 7.6 & 13.3 & Response to glucocorticoid stimulus \\
\hline Tal2 & $\begin{array}{l}\text { T-cell acute lymphocytic } \\
\text { leukemia protein } 2\end{array}$ & 11.8 & 132.8 & Transcription regulator activity, DNA binding \\
\hline \multicolumn{5}{|c|}{ B. Pineal: Differentially expressed genes in cKO versus CON } \\
\hline NeuroD1 & $\begin{array}{l}\text { Neurogenic differentiation } \\
1 \text { transcription factor }\end{array}$ & -47.8 & -196.5 & $\begin{array}{l}\text { Transcription activator activity, Photoreceptor } \\
\text { cell development }\end{array}$ \\
\hline S100a8 & $\begin{array}{l}\text { S100 calcium-binding protein } \\
\text { A8 (calgranulin A) }\end{array}$ & -3.3 & -4.4 & $\begin{array}{l}\text { Chemotaxis, calcium binding, inflammatory } \\
\text { response }\end{array}$ \\
\hline S100a9 & $\begin{array}{l}\text { S100 calcium-binding protein } \\
\text { A9 (calgranulin B) }\end{array}$ & -3.1 & -4.3 & Actin cytoskeleton reorganization, calcium binding \\
\hline Fli-1 & $\begin{array}{l}\text { Friend leukemia integration } \\
1 \text { transcription factor }\end{array}$ & -2.5 & -3.4 & Regulation of transcription, DNA dependent \\
\hline Agr2 & $\begin{array}{l}\text { Anterior gradient homolog } \\
2 \text { (Xenopus laevis) }\end{array}$ & -2.2 & -3.4 & Protein binding \\
\hline Per3 & Period 3 & -2.1 & -1.6 & $\begin{array}{l}\text { Regulation of transcription, DNA-dependent, } \\
\text { rhythmic process }\end{array}$ \\
\hline Dsp & Desmoplakin & 2.2 & 2.8 & Beta catenin signaling \\
\hline Prlr & Prolactin receptor & 2.2 & 2.6 & Cytokine receptor degradation signaling \\
\hline Igl-V1 & $\begin{array}{l}\text { Immunoglobulin lambda } \\
\text { chain, variable } 1\end{array}$ & 9.1 & 7.2 & B-cell signaling, Immune response \\
\hline
\end{tabular}

See Appendix S1 for further details.

affected group of genes to promoters from the entire genome (Z-score $>2, p<0.05$ ). NeuroD1-binding sites were present in the promoters of several photoreceptor transduction genes including Opn1mw, Aipl1, Agr2, and Ankrd33 in the retina (Fig. 5a), and S100a8, S100a9, Per3, and Agr2 in the pineal gland (Fig. 5b). NeuroD1 dimerizes with its binding partner E47, a bHLH transcription factor, and forms a heterodimer NeuroD1/E47 to translocate to the nucleus and regulate transcription of target genes (Mehmood et al. 2011, 2009; Longo et al. 2008). Promoter analysis of the most affected genes using the MatInspector platform revealed that all of the down-regulated genes in the retina contain potential binding sites for the heterodimer NeuroD1/E47 (Fig. 5a). Only two down-regulated genes in the pineal gland, Agr2 and S100a9, contain putative binding sites for the NeuroD1/ E47 complex (Fig. 5b).

The list of genes with altered rhythmic expression on a night/day basis in the retina and pineal gland (Table 3) was analyzed using Genomatix software. To determine whether there was enrichment in specific transcription factor modules which included the NeuroD1/E47 binding site, we used the transcription factor overrepresentation search in Gen- 
Table 3 Genes exhibiting a night/day rhythm in the control and/or NeuroD1 cKO retina and pineal gland. (A) This section of the table depicts three categories of gene groups found in the control and NeuroD1 cKO retina: Genes that are rhythmic in both the control and cKO retina; genes that become arrhythmic in the cKO retina; and genes that gain rhythmicity in the cKO retina. (B) This section of the table depicts three categories of gene groups found in the control and cKO pineal gland: Genes that are rhythmic in both the control and cKO pineal gland; genes that become arrhythmic in the cKO pineal gland; and genes that gain rhythmicity in the cKO pineal gland. See Appendix S1 for further details

\begin{tabular}{|c|c|c|c|}
\hline Night/Day Ratio & Rhythmic in CON and cKO & Rhythmic in CON & Rhythmic in cKO \\
\hline \multicolumn{4}{|c|}{ A. Retina: Genes exhibiting a night/day rhythm in $\mathrm{CON}$ and cKO } \\
\hline $2-4$ & Irf7, Pgbd1, Nr4a1, Sik2, Zdhhc5 & Casz1, Aqp1, Hspa1b, Thbs1, Drd4 & $\begin{array}{l}\text { Gsta3, Trpm1, Atp1a2, } \\
\text { Slc13a4, Fbin1, Rorb, Gpx3 }\end{array}$ \\
\hline $1 / 2-1 / 4$ & $\begin{array}{l}\text { Col19a1, Dynlarb2, Phospho2, } \\
\text { Glmn, Taf4b }\end{array}$ & $\begin{array}{l}\text { Dnase2b, Krt6b, Krt15, Emp1, Sgcg, } \\
\text { Crh, Lenep, Flad1, Pgam2, Eif2s3y, } \\
\text { Slamf1, Kdm5d, Dio2, Dleu7, Ccl9, } \\
\text { Rprd2, Ucma }\end{array}$ & Akap5, Tmem116, Ly75, Adcy1 \\
\hline \multicolumn{4}{|c|}{ B. Pineal: Genes exhibiting a night/day rhythm in $\mathrm{CON}$ and cKO } \\
\hline $8-12$ & Gng4, E2f8, Aanat, Cpm & - & - \\
\hline $4-8$ & $\begin{array}{l}\text { Stc2, Kcnc1, Gulo, Piwil4, Pgbd1, } \\
\text { Tbc1d1, Ifng, Dclk1, Ednrb, }\end{array}$ & Frmd1 & Slc6a5, St8sia2, Grm4, \\
\hline $2-4$ & Gls2, Lrfn2, Kif5c, Cckbr, Rftn1, Adra1b & Cyth3, Ednra, Plekho2, Odc1, Rimkla & Dlk1, Nr4a1, Ppa2, Pparg \\
\hline $1 / 2-1 / 4$ & $\begin{array}{l}\text { Hspa12a, Dpp10, Ppp2r2b, Cntn4, } \\
\text { Wdr17, Nr1d1, Gabra1, Nrxn3 }\end{array}$ & Ifi202b, Ifi203, Tmem90a, Mtap2 & $\begin{array}{l}\text { Caccnb2, Adcy1, Bai3, Opn1sw, } \\
\text { IsI2, Fam19a3, Ush2a }\end{array}$ \\
\hline $1 / 4-1 / 8$ & Clca3 & & \\
\hline
\end{tabular}

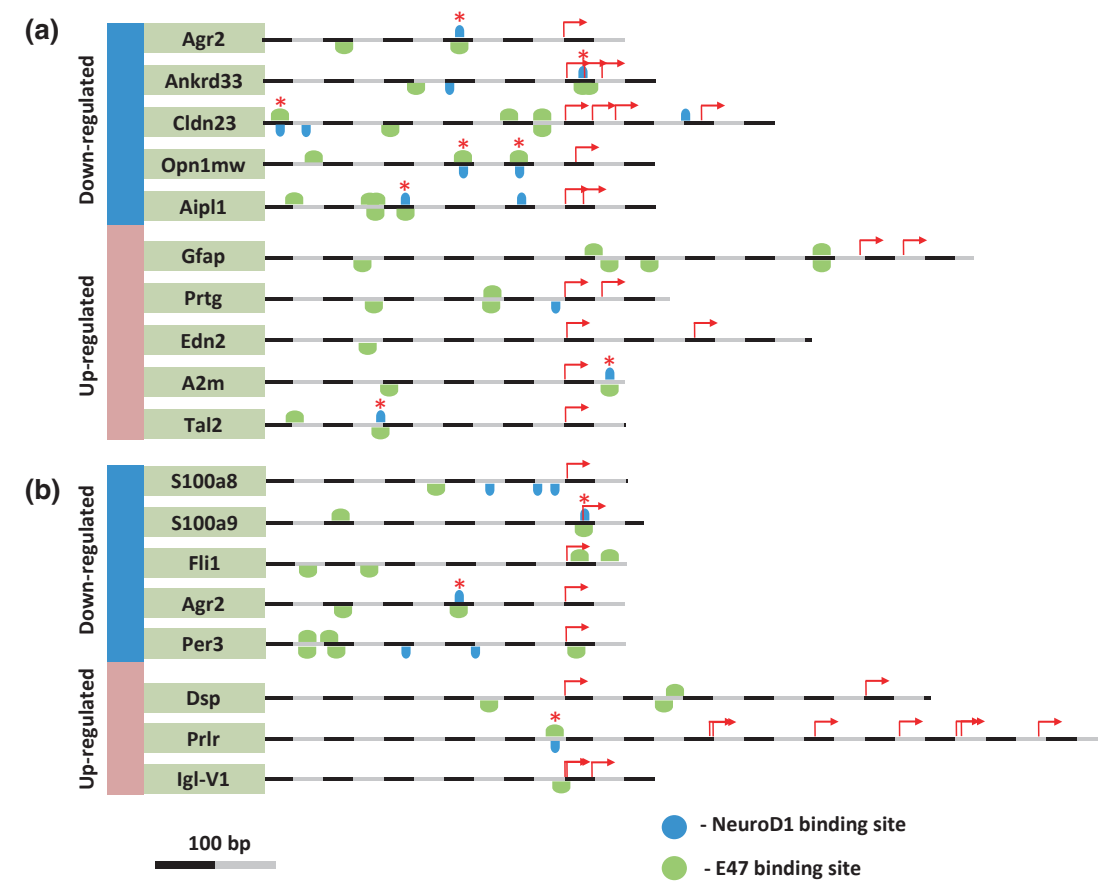

Fig. 5 In silico Promoter analysis of differentially expressed genes in the NeuroD1 conditional knockout retina and pineal gland using Genomatix software. (a) Promoter analysis of the most affected genes in the conditional knockout retina using the Genomatix MatInspector platform. NeuroD1-binding sites are labeled in blue and E47-binding sites are labeled in green. All of the down-regulated genes identified in the retina contain putative active binding sites for both NeuroD1 and its partner E47 (red asterisks). Potential DNA-binding sites for the hete- rodimer NeuroD1/E47 are present in two of the five up-regulated genes analyzed, $A 2 m$ and Tal2. (b) Promoter analysis of the most affected genes in the conditional knockout pineal gland using the Genomatix Matlnspector platform. The down-regulated genes Agr2 and $5100 a 9$ in the pineal gland contain putative active binding sites for the heterodimer NeuroD1/E47. Prlrgene is the only up-regulated gene with this class of DNA-binding site. See Appendix S1 for further details. 
omatix. This analysis revealed that several transcription factor modules containing NeuroD1 were overrepresented in the genes with altered rhythms in both the retina and pineal gland with Z-scores > 4.0 (Table S1). The most overrepresented modules included the Krüppel-like transcription factor family in the retina $(Z$-score $=8.1)$ and the GATA-binding factor family in the pineal gland (Zscore $=5.0$ ).

\section{Electroretinography}

Rod and cone ERGs are severely compromised in NeuroDl cKO mice

The role of NeuroD1 in visual physiology was analyzed in NeuroDl cKO mice by electoretinography. Rod- and conemediated ERGs were recorded to evaluate retinal function in NeuroD1 cKO mice. Four animals per genotype were analyzed (cKO, $n=4$; $\mathrm{CON}, n=4)$ at 2 and at 4 months of age. At 2 months of age, cKO mice showed significant reductions in rod-driven ERG responses compared with controls (Fig. 6a and 6c; * $p<0.001$ ). Cone ERG responses in cKO mice were reduced to undetectable levels at 2 months of age (Fig. $6 \mathrm{~b}$ and d; $* p<0.001$ ). Rod and cone ERG responses in the cKO retina were undetectable at 4 months of age (data not shown).
Cone and rod ERGs in the Agr2 $2^{-1}$ mice are normal The finding that selective knockout of NeuroDl decreases the abundance of Agr2 transcripts raised the possibility that Agr2 deletion would cause retinal damage. To test this hypothesis, we examined rod and cone electroretinogram responses in $A g r 2^{-1-}(\mathrm{KO})$ and control $(\mathrm{CON})$ mice. Four animals per genotype were analyzed (KO, $n=4$; $\mathrm{CON}, n=4)$ at 2 and 4 months of age. $A g r 2^{-/-}$mice displayed normal rod and cone ERGs at both ages (Fig. 7a and b). Significant differences between the average rod- and cone-driven b-wave amplitudes were not detected at these ages (Fig. $7 \mathrm{c}$ and d) or at 6 months of age (data not shown).

\section{Discussion}

This is the first report on the effect of tissue-specific NeuroDl knockout in the adult mouse retina and pineal gland. Analysis of NeuroDl cKO retina and pineal gland revealed a marked reduction in NeuroD1 transcript and severely compromised photoreceptor function. This confirmed that the targeted knockout strategy was effective and establishes a useful model for studies of NeuroD1. The results of this study are discussed below from retinal and pineal perspectives, sequentially.

\section{NeuroD1 cKO vs. CON}
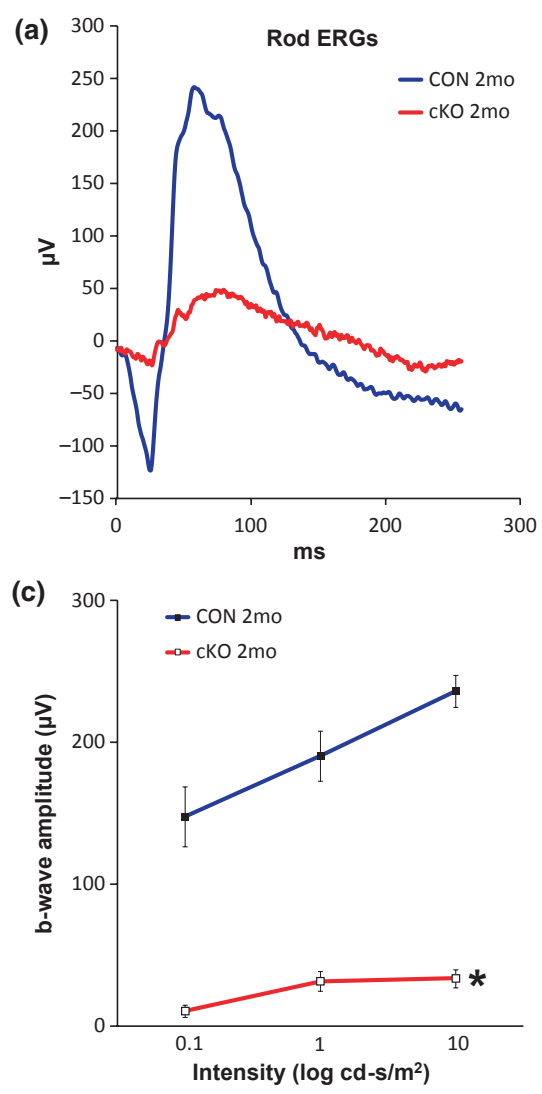

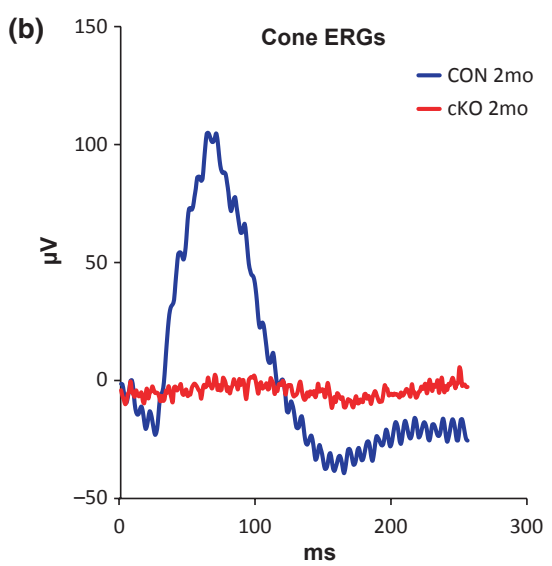

(d)

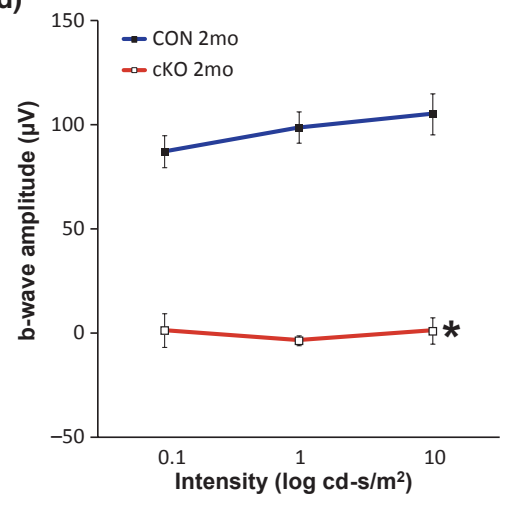

Fig. 6 Electroretinograms from NeuroD1 conditional knockout (cKO) mice compared to controls at 2 and 4 months of age. (a and b) NeuroD $1 \mathrm{cKO}$ animals are nearly blind by 2 months of age based on rod- and conedriven electroretinogram responses. (c and d) The average rod- and cone-driven bwave amplitudes, respectively, at different light intensities for $\mathrm{CKO}$ and control animals at 2 months of age. Statistically significant reduction in rod and cone amplitudes at the highest intensity measured: ${ }^{*} p<0.001$. See Appendix $\mathrm{S} 1$ for further details. 
Fig. 7 Electroretinograms from Agr2 KO mice compared to controls at 2 and 4 months of age. ( $a$ and $b$ ) In contrast to the NeuroD1 cKO mice, Agr2 KO animals do not show altered rod- or cone-driven electroretinograms at either 2 or 4 months of age. (c and d) Average rod- and cone-driven B-wave amplitudes, respectively, for $\mathrm{KO}$ and control animals at 2 and 4 months of age. See Appendix $\mathrm{S} 1$ for further details.

\section{Agr2 KO vs. CON}
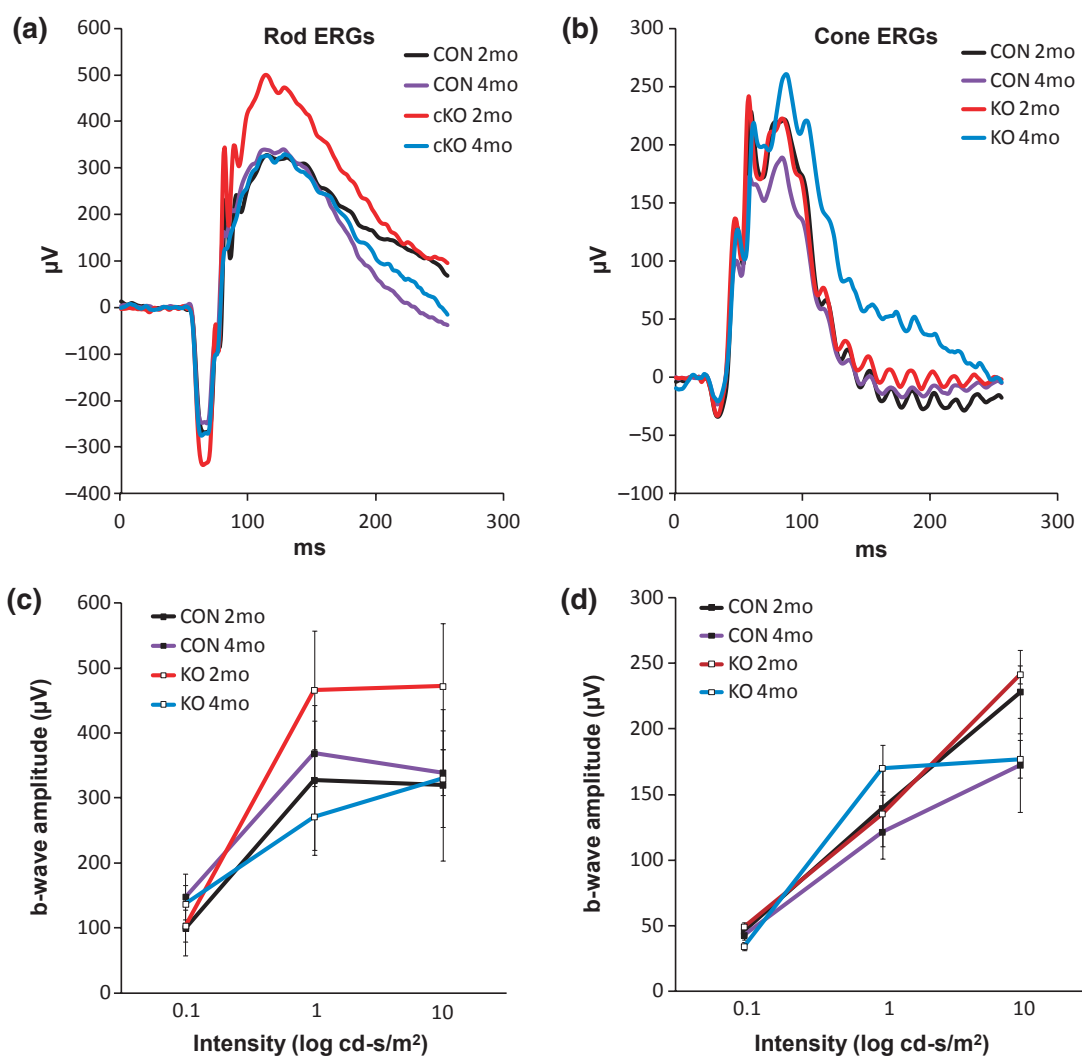

\section{Role of NeuroD1 in retinal biology}

This study extends our understanding of the sequence of events involved in retinal degeneration induced by NeuroD1 deletion, which we view as a two-stage process (Table 4). The first stage is characterized by marked reduction of photodetection as indicated by electroretinography, by changes in outer segments, and by a profound decrease in Rho. However, at this stage, the photoreceptor cell bodies appear to be histologically intact. In agreement, photodetector marker genes remain strongly expressed including transduction genes (e.g., Rho, Gnat1, Rcvrn, Sag, Arr3, Pde6, and Grk1) and transcription factor genes (e.g., Crx, $\mathrm{Nrl}$, and Otx2). Moreover, the expression of thousands of other genes is also normal. This supports the interpretation that at this stage, the cell bodies are not globally impacted by the loss of NeuroD1. However, a notable outstanding change observed is a $95 \%$ reduction in Rho. The second stage of photoreceptor deterioration is characterized by absence of photoreceptors, as observed by 4 months of age.

The contrast between the marked change in ERG and the minor change in gene expression at 2 months suggests that one or all of the small number of genes that are most affected at this time play a critical role in the loss of photodetection and in disruption of outer segments without marked destruction of cell bodies. This group includes Aipll, Ankyrd33/Panky, and Agr2. We suspect that the reduction in expression of one or more of these genes and their encoded proteins is critical for the initial deterioration of outer segments. Furthermore, the presence of putative binding sites in the promoters of these affected genes suggests that NeuroD1 acts directly on these genes.

Aipll has been linked to Leber's congenital amarousis, one of the earliest onset and the most severe forms of inherited retinopathy in humans (Ramamurthy et al. 2004). Experimental deletion of Aipll causes a retinal phenotype remarkably similar to the one described in this study: compromised ERGs, altered structural integrity of the outer segment and the retinal pigment epithelium boundary, and photoreceptor-specific degeneration (Ramamurthy et al. 2004; Dyer et al. 2004). Hence, the NeuroD1-Aipll link established in this study is of special interest because it raises the possibility that retinal pathologies could reflect a reduction in NeuroD1-dependent gene expression, leading to a reduction in Aipll expression, which leads to loss of phototransduction.

A second factor that might contribute to the observed effects of NeuroDl cKO is Ankyrd33/Panky, which encodes a transcriptional cofactor that suppresses Crx-dependent pho- 
Table 4 The two stages of photoreceptor degeneration phenotype observed in the NeuroD1 cKO retina

\begin{tabular}{|c|c|c|}
\hline Photoreceptors & 2 months & 4 months \\
\hline \multicolumn{3}{|l|}{ Rods } \\
\hline Morphology & $\begin{array}{l}\text { Outer segments shortened } \\
\text { and disorganized, cell } \\
\text { bodies present }\end{array}$ & ONL absent \\
\hline Rho protein & $\begin{array}{l}\text { Rho partially mislocalized } \\
\text { to inner segment; reduced } 95 \%\end{array}$ & $\mathrm{~N} / \mathrm{A}$ \\
\hline Rho mRNA & Reduced $40 \%$ & $\mathrm{~N} / \mathrm{A}$ \\
\hline ERG & Significantly reduced & N/D \\
\hline \multicolumn{3}{|l|}{ M-cones } \\
\hline Morphology & Nearly absent & ONL absent \\
\hline M-Opsin protein & Nearly absent & $\mathrm{N} / \mathrm{A}$ \\
\hline M-Opsin mRNA & Reduced $80 \%$ & $\mathrm{~N} / \mathrm{A}$ \\
\hline ERG & $\mathrm{N} / \mathrm{D}$ & N/D \\
\hline \multicolumn{3}{|l|}{ S-cones } \\
\hline Morphology & $\begin{array}{l}\text { Outer segments disorganized, } \\
\text { cell bodies present }\end{array}$ & ONL absent \\
\hline S-Opsin protein & $\begin{array}{l}\text { S-opsin mislocalized to cell } \\
\text { membrane and synapse }\end{array}$ & $\mathrm{N} / \mathrm{A}$ \\
\hline S-Opsin mRNA & No change & $\mathrm{N} / \mathrm{A}$ \\
\hline ERG & $\mathrm{N} / \mathrm{D}$ & N/D \\
\hline
\end{tabular}

At 2 months of age the absence of NeuroD1 leads to selective degeneration of the outer segments and reduced or absent electroretinogram (ERG) responses. In turn, this loss of outer segments and associated changes may lead to the disappearance of the photoreceptor cell bodies, as observed by 4 months of age. The outer nuclear layer (ONL), which contains both the cone and rod photoreceptor cell bodies, is absent by 4 months of age. ONL, outer nuclear layer; N/D, Not Detected; N/A, Not Analyzed. See Appendix S1 for further details.

toreceptor genes (Sanuki et al. 2010). Accordingly, downregulation of Ankrd33/Panky may remove suppression of a gene that has a negative influence on photoreceptor biology. An Ankyrd33/Panky knockout mouse model is not available, but our expression data, as well as other gene profiling data, suggest that Ankyrd33 is a good retinal degeneration candidate gene (Geisert et al. 2009; Sanuki et al. 2010).

Decreased expression of Agr2 may also contribute to the loss of photoreceptor function through an effect on protein folding. This gene encodes a protein disulfide isomerase (Park et al. 2009; Persson et al. 2005); members of this family ensure that proper disulfide bonds are formed in newly synthesized proteins. Proper formation of disulfides is required for normal protein function; an example from the retina literature is Rho (McKibbin et al. 2007), misfolding of which prevents membrane insertion and proper function. Accordingly, it is possible that the decrease in Agr2 transcripts contributes to the observed effects because substrates of this enzyme, perhaps Rho, are incorrectly folded. However, the finding that $\mathrm{Agr} 2^{-/-}$animals have normal ERG responses and relatively normal photoreceptor morphology indicates that loss of Agr2 alone does not explain the observed NeuroD1 cKO phenotype. Accordingly, it seems valuable to consider that $A g r 2$ might contribute to photoreceptor physiology and that photoreceptor loss in the NeuroD1 cKO mouse reflects the impact of the partially reduced expression of it, together with that of Aipll and Ankyrd33/Panky.

The observations in this study are consistent with the interpretation that the gradual loss of photoreceptor cell bodies may involve an immune response in which the initial deterioration of outer segments leads to destruction of photoreceptor cell bodies (Whitcup et al. 1998). This is consistent with the increased expression of genes associated with the immune response including Gfap, Prtg, Edn2, A2m, and Tal2. The most highly up-regulated (>11-fold) gene is T-cell acute lymphocytic leukemia 2 (Tal2), that encodes a bHLH transcription factor, which functions as an oncogene whose activation can lead to T-cell leukemia, a cancer of the immune system (Bucher et al. 2000; Xia et al. 1994; Wadman et al. 1994).

NeuroD1 also plays a role in cone photoreceptor specification via regulation of thyroid hormone receptor beta2 (TRbeta2) expression (Liu et al. 2008). We found similar effects on cone photoreceptor specification, but did not observe a change in expression of TRbeta 2 at 2 months of age. However, the study by Liu et al. (2008) involved embryonic total-NeuroD1 knockout and evaluated early postnatal retinal explants; in contrast, in this study, NeuroDl was deleted late in gestation and adult tissue was evaluated. Therefore, it is possible that the differing results in the two studies reflect differences in the timing of the knockout and in the developmental stages examined.

\section{Role of NeuroD1 in pineal biology}

In contrast to the retina, deletion of NeuroD1 did not cause obvious pineal gland morphological effects, although shorter and wider pineal stalks were consistently observed. Deletion of NeuroD1 did not affect expression of phototransductionor melatonin synthesis-related genes in the pineal gland, consistent with previous findings in neonatal mice (Muñoz et al. 2007). This suggests that NeuroD1 is not an essential regulator of the melatonin synthesis pathway, but does not eliminate the possibility that it is involved in modulating other aspects of pineal biology, including transcription and calcium signaling, processes which are linked to S100a8 and S100a9 (Ghavami et al. 2009); expression of which was suppressed in the NeuroDl KO pineal gland.

Comparison of the results of this study with the previous study on NeuroD1 deletion in neonatal mice reveals notable differences. Total knockout of NeuroD1 results in increased expression of Kif5c and Gad1 (Muñoz et al. 2007) in the neonatal pineal gland; this was not observed in this study of the adult pineal gland in which the gene deletion occurs late 
(a) Retina

(b) Pineal gland

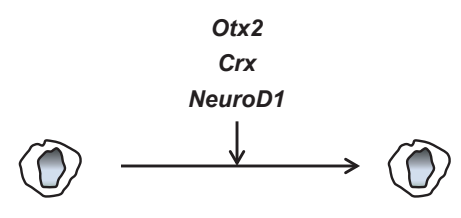

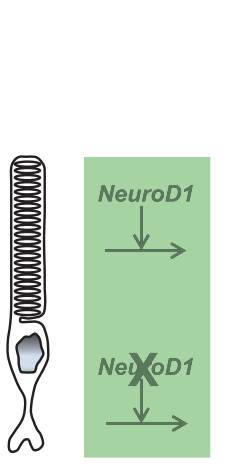

Homeostasis

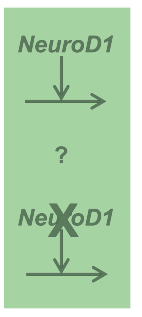

NeuroD1 downstream targets:

Agr2*

Ankrd33*

Cldn23*

Opn1mw*

Aip/1*
Fig. 8 Schematic diagram illustrating NeuroD1 and its downstream targets in the photoreceptor and pinealocyte lineages. (a) Photoreceptor progenitors express Otx2 and Crx. Differentiated photoreceptors express NeuroD1 required for photoreceptor survival through a network of downstream targets including: Agr2, Ankrd33, Cldn23, Opn1mw, and Aip/1. (b) Pinealocyte progenitors express Otx2 and
Crx. Differentiated pinealocytes express NeuroD1, which may play a role in maintenance of pinealocytes through a network of downstream targets including S100a8, S100a9, Agr2, Fli-1, and Per3. Asterisks denote genes with promoters containing putative active NeuroD1/E47binding sites. The five most strongly down-regulated genes in both the retina and pineal gland are illustrated. in gestation, when $\mathrm{Crx}$ is first expressed. Accordingly the differences may reflect differences in the timing of NeuroD1 deletion and in the ages studied. It is likewise reasonable to suspect that NeuroD1 may play different roles during pineal development because NeuroD1 may control transcription in concert with other factors (Cherry et al. 2011); different combinations of which in the neonatal versus the adult pineal gland could have differential effects on gene expression.

Day-night analyses of the mouse pineal transcriptome have been previously published (Rovsing et al. 2011). Those analyses revealed significant differences in the abundance of rhythmic genes between species: In contrast to $>600$ genes found to be rhythmic in the rat pineal gland (Bailey et al. 2009), only 51 genes showed a day/night rhythm in 129 sv mice (Rovsing et al. 2011). We compared the list of 51 genes that were rhythmically expressed in $129 \mathrm{sv}$ mice (Rovsing et al. 2011) with the list of 38 genes that were rhythmic in the NeuroD1 control pineal glands, which are on a C57BL/6J background. Of the 51 genes that were rhythmically expressed on a day-night basis in the $129 \mathrm{sv}$ control pineal glands, only 15 were also rhythmic in the C57BL/6J; these included melatonin and signal transduction genes Aanat, Gng4, E2f8, Cpm, Nrld1, and Nrxn3 (Rovsing et al. 2011). This indicates that there are notable strain differences in rhythmic gene expression in this tissue and perhaps others.

\section{Concluding remarks}

The findings of this report confirm that NeuroDl is required for photoreceptor function and indicate that it may act through a small set of genes to promote retinal survival, specifically through the maintenance of photoreceptor outer segments, loss of which results in photoreceptor degeneration. NeuroD1 may also play a role in pinealocyte homeostasis. The advances from our study are summarized in Fig. 8, which describes the expression of NeuroD1 and its downstream targets in the photoreceptor and pinealocyte lineages. The absence of NeuroD1 and its downstream targets results in deterioration of outer segments and leads to the progressive degeneration of photoreceptor cell bodies. The NeuroD1-Aipll link established in this study raises the possibility that retinal pathologies could, in part, reflect a reduction in NeuroD1-dependent gene expression, which in turn could suppress expression of Aipll and other genes required for photoreceptor homeostasis. 


\section{Acknowledgements}

This research was supported by the Intramural Research Program of the National Institute of Child Health and Human Development, NIH grants R01EY004864 and P30EY006360, and an unrestricted departmental grant from Research to Prevent Blindness, Inc. (RPB). PMI is a recipient of a Senior Scientific Investigator Award from RPB. We would like to thank members of the Klein laboratory, Dr. Morten Møller and Dr. James Russell for many helpful discussions, Dr. Cheryl Craft for the gift of S-opsin and M-opsin antisera, Dr. Robert Molday for the gift of the Rho (Rho 4D2) antiserum, Dr. David J. Erle for the gift of $A g r 2^{+/-}$mice, Chip Dye (NICHD Microscopy and Imaging Core) for his help with transmission electron microscopy, Dr. Anand Swaroop and members of the Neurobiology-Neurodegeneration and Repair Laboratory, and Dr. Haohua Qian in the NEI Visual Function Core for assistance with electroretinography, and Daniel Abebe for his veterinary support.

\section{Conflict of interest}

None

\section{Supporting information}

Additional supporting information may be found in the online version of this article:

Appendix S1. Supplementary materials and methods.

Table S1. Overrepresented transcription factor regulatory elements forming modules with the NeuroD1 binding site (V\$NEUR).

As a service to our authors and readers, this journal provides supporting information supplied by the authors. Such materials are peer-reviewed and may be re-organized for online delivery, but are not copy-edited or typeset. Technical support issues arising from supporting information (other than missing files) should be addressed to the authors.

\section{References}

Armitage P., Berry G. and Matthews J. N. S. (2002) Statistical Methods in Medical Research (4th edition). Blackwell Science, Oxford.

Babila T., Schaad N. C., Simonds W. F., Shinohara T. and Klein D. C. (1992) Development of MEKA (phosducin), G beta, G gamma and S-antigen in the rat pineal gland and retina. Brain Res. 585, 141148.

Bailey M. J., Coon S. L., Carter D. A. et al. (2009) Night/day changes in pineal expression of $>600$ genes: central role of adrenergic/cAMP signaling. J. Biol. Chem. 284, 7606-7622.

Bucher K., Sofroniew M. V., Pannell R. et al. (2000) The T cell oncogene Tal2 is necessary for normal development of the mouse brain. Dev. Biol. 227, 533-544.

Cai L., Morrow E. M. and Cepko C. L. (2000) Misexpression of basic helix-loop-helix genes in the murine cerebral cortex affects cell fate choices and neuronal survival. Development 127, 3021-3030.

Cherry T. J., Wang S., Bormuth I., Schwab M., Olson J. and Cepko C. L. (2011) NeuroD factors regulate cell fate and neurite stratification in the developing retina. J. Neurosci. 31, 7365-7379.

Das S., Hirano M., McCallister C., Tako R. and Nikolaidis N. (2011) Comparative genomics and evolution of immunoglobulin-encoding loci in tetrapods. Adv. Immunol. 111, 143-178.
Donoso L. A., Merryman C. F., Edelberg K. E., Naids R. and Kalsow C. (1985) S-antigen in the developing retina and pineal gland: a monoclonal antibody study. Invest Ophthalmol. Vis. Sci. 26, 561567.

Dyer M. A., Donovan S. L., Zhang J., Gray J., Ortiz A., Tenney R., Kong J., Allikmets R. and Sohocki M. M. (2004) Retinal degeneration in Aipl1-deficient mice: a new genetic model of Leber congenital amaurosis. Brain Res. Mol. Brain Res. 132, 208-220.

Edgar R., Domrachev M. and Lash A. E. (2002) Gene Expression Omnibus: NCBI gene expression and hybridization array data repository. Nucleic Acids Res. 30, 207-10.

Fan W., Li X., Wang W., Mo J. S., Kaplan H. and Cooper N. G. (2010) Early involvement of immune/inflammatory response genes in retinal degeneration in DBA/2J mice. Ophthalmol. Eye Dis. 1, $23-41$.

Furukawa A., Koike C., Lippincott P., Cepko C. L. and Furukawa T. (2002) The mouse Crx 5'-upstream transgene sequence directs cellspecific and developmentally regulated expression in retinal photoreceptor cells. J. Neurosci. 22, 1640-1647.

Geisert E. E., Lu L., Freeman-Anderson N. E., Templeton J. P., Nassr M., Wang X., Gu W., Jiao Y. and Williams R. W. (2009) Gene expression in the mouse eye: an online resource for genetics using 103 strains of mice. Mol. Vis. 15, 1730-1763.

Ghavami S., Chitayat S., Hashemi M., Eshraghi M., Chazin W. J., Halayko A. J. and Kerkhoff C. (2009) S100A8/A9: a Janus-faced molecule in cancer therapy and tumorgenesis. Eur. J. Pharmacol. 625, 73-83.

Goebbels S., Bode U., Pieper A., Funfschilling U., Schwab M. H. and Nave K. A. (2005) Cre/loxP-mediated inactivation of the bHLH transcription factor gene NeuroD/BETA2. Genesis, 42, 247-252.

Klein D. C. (2006) Evolution of the vertebrate pineal gland: the AANAT hypothesis. Chronobiol. Int. 23, 5-20.

Korf H. W., Foster R. G., Ekstrom P. and Schalken J. J. (1985) Opsinlike immunoreaction in the retinae and pineal organs of four mammalian species. Cell Tissue Res. 242, 645-648.

Korf H. W., White B. H., Schaad N. C. and Klein D. C. (1992) Recoverin in pineal organs and retinae of various vertebrate species including man. Brain Res. 595, 57-66.

Kumar A. and Shamsuddin N. (2012) Retinal Muller glia initiate innate response to infectious stimuli via toll-like receptor signaling. PLoS One 7, e29830.

Lee J. K., Cho J. H., Hwang W. S., Lee Y. D., Reu D. S. and Suh-Kim H. (2000) Expression of neuroD/BETA2 in mitotic and postmitotic neuronal cells during the development of nervous system. Dev. Dyn. 217, 361-367.

Lewandoski M., Meyers E. N. and Martin G. R. (1997) Analysis of Fgf8 gene function in vertebrate development. Cold Spring Harb. Symp. Quant. Biol. 62, 159-168.

Liu M., Pereira F. A., Price S. D. et al. (2000) Essential role of BETA2/ NeuroD1 in development of the vestibular and auditory systems. Genes Dev. 14, 2839-2854.

Liu H., Etter P., Hayes S., Jones I., Nelson B., Hartman B., Forrest D. and Reh T. A. (2008) NeuroD1 regulates expression of thyroid hormone receptor 2 and cone opsins in the developing mouse retina. J. Neurosci. 28, 749-756.

Lolley R. N., Craft C. M. and Lee R. H. (1992) Photoreceptors of the retina and pinealocytes of the pineal gland share common components of signal transduction. Neurochem. Res. 17, 81-89.

Longo A., Guanga G. P. and Rose R. B. (2008) Crystal structure of E47NeuroD1/beta2 bHLH domain-DNA complex: heterodimer selectivity and DNA recognition. Biochemistry 47, 218-229.

McKibbin C., Toye A. M., Reeves P. J., Khorana H. G., Edwards P. C., Villa C. and Booth P. J. (2007) Opsin stability and folding: the role 
of Cys 185 and abnormal disulfide bond formation in the intradiscal domain. J. Mol. Biol. 374, 1309-1318.

Mehmood R., Yasuhara N., Oe S., Nagai M. and Yoneda Y. (2009) Synergistic nuclear import of NeuroD1 and its partner transcription factor, E47, via heterodimerization. Exp. Cell Res. 315, 1639-1652.

Mehmood R., Yasuhara N., Fukumoto M., Oe S., Tachibana T. and Yoneda Y. (2011) Cross-talk between distinct nuclear import pathways enables efficient nuclear import of E47 in conjunction with its partner transcription factors. Mol. Biol. Cell 22, 37153724.

Miyata T., Maeda T. and Lee J. E. (1999) NeuroD is required for differentiation of the granule cells in the cerebellum and hippocampus. Genes Dev. 13, 1647-1652.

Møller M., van Deurs B. and Westergaard E. (1978) Vascular permeability to proteins and peptides in the mouse pineal gland. Cell Tissue Res. 195, 1-15.

Morrow E. M., Furukawa T., Lee J. E. and Cepko C. L. (1999) NeuroD regulates multiple functions in the developing neural retina in rodent. Development 126, 23-36.

Muñoz E. M., Bailey M. J., Rath M. F., Shi Q., Morin F., Coon S. L., Møller M. and Klein D. C. (2007) NeuroD1: developmental expression and regulated genes in the rodent pineal gland. J. Neurochem. 102, 887-899.

Ochocinska M. J. and Hitchcock P. F. (2009) NeuroD regulates proliferation of photoreceptor progenitors in the retina of the zebrafish. Mech. Dev. 126, 128-141.

Omori Y., Araki F., Chaya T. et al. (2012) Presynaptic dystroglycanpikachurin complex regulates the proper synaptic connection between retinal photoreceptor and bipolar cells. J. Neurosci. 32, 6126-6137.

Pang J. J., Chang B., Hawes N. L. et al. (2005) Retinal degeneration 12 (rd12): a new, spontaneously arising mouse model for human Leber congenital amaurosis (LCA). Mol. Vis. 11, 152-162.

Park S. W., Zhen G., Verhaeghe C., Nakagami Y., Nguyenvu L. T., Barczak A. J., Killeen N. and Erle D. J. (2009) The protein disulfide isomerase AGR2 is essential for production of intestinal mucus. Proc. Natl. Acad. Sci. USA 106, 6950-6955.

Pennesi M. E., Cho J. H., Yang Z., Wu S. H., Zhang J., Wu S. M. and Tsai M. J. (2003) BETA2/NeuroD1 null mice: a new model for transcription factor-dependent photoreceptor degeneration. J. Neurosci. 23, 453-461.

Persson S., Rosenquist M., Knoblach B., Khosravi-Far R., Sommarin M. and Michalak M. (2005) Diversity of the protein disulfide isomerase family: identification of breast tumor induced Hag2 and Hag3 as novel members of the protein family. Mol. Phylogenet. Evol. 36, 734-740.

Ramamurthy V., Niemi G. A., Reh T. A. and Hurley J. B. (2004) Leber congenital amaurosis linked to AIPL1: a mouse model reveals destabilization of cGMP phosphodiesterase. Proc. Natl. Acad. Sci. USA 101, 13897-13902.

Rath M. F., Muñoz E., Ganguly S., Morin F., Shi Q., Klein D. C. and Møller M. (2006) Expression of the Otx2 homeobox gene in the developing mammalian brain: embryonic and adult expression in the pineal gland. J. Neurochem. 97, 556-566.

Rattner A. and Nathans J. (2005) The genomic response to retinal disease and injury: evidence for endothelin signaling from photoreceptors to glia. J. Neurosci. 25, 4540-4549.

Reig J. A., Yu L. and Klein D. C. (1990) Pineal transduction. Adrenergic_-cyclic AMP-dependent phosphorylation of cytoplasmic 33-kDa protein (MEKA) which binds beta gamma-complex of transducin. J. Biol. Chem. 265, 5816-5824.

Rodrigues M. M., Hackett J., Gaskins R., Wiggert B., Lee L., Redmond M. and Chader G. J. (1986) Interphotoreceptor retinoid-binding protein in retinal rod cells and pineal gland. Invest Ophthalmol. Vis. Sci. 27, 844-850.

Rovsing L., Clokie S., Bustos D. M., Rohde K., Coon S. L., Litman T., Rath M. F., Møller M. and Klein D. C. (2011) Crx broadly modulates the pineal transcriptome. J. Neurochem. 119, 262-274.

Sanuki R., Omori Y., Koike C., Sato S. and Furukawa T. (2010) Panky, a novel photoreceptor-specific ankyrin repeat protein, is a transcriptional cofactor that suppresses CRX-regulated photoreceptor genes. FEBS Lett. 584, 753-758.

Schaad N. C., Shinohara T., Abe T. and Klein D. C. (1991) Photoneural control of the synthesis and phosphorylation of pineal MEKA (phosducin). Endocrinology 129, 3289-3298.

Schwab M. H., Bartholomae A., Heimrich B. et al. (2000) Neuronal basic helix-loop-helix proteins (NEX and BETA2/Neuro D) regulate terminal granule cell differentiation in the hippocampus. J. Neurosci. 20, 3714-3724.

Takahashi K. F., Kiyoshima T., Kobayashi I. et al. (2010) Protogenin, a new member of the immunoglobulin superfamily, is implicated in the development of the mouse lower first molar. BMC Dev. Biol. $10,115$.

Wadman I., Li J., Bash R. O., Forster A., Osada H., Rabbitts T. H. and Baer R. (1994) Specific in vivo association between the bHLH and LIM proteins implicated in human T cell leukemia. EMBO J. 13, 4831-4839.

Whitcup S. M., Vistica B. P., Milam A. H., Nussenblatt R. B. and Gery I. (1998) Recoverin-associated retinopathy: a clinically and immunologically distinctive disease. Am. J. Ophthalmol. 126, 230-237.

Wojtowicz J. M. and Kee N. (2006) BrdU assay for neurogenesis in rodents. Nat. Protoc. 1, 1399-1405.

Xia Y., Hwang L. Y., Cobb M. H. and Baer R. (1994) Products of the TAL2 oncogene in leukemic T cells: bHLH phosphoproteins with DNA-binding activity. Oncogene 9, 1437-1446. 